\title{
Ecological Restoration of Degraded Supratidal Wetland Based on Microtopography Modification: a Case Study in the Yellow River Delta
}

\author{
Guangmei Wang ${ }^{1,2} \cdot$ Juanzhang $\mathrm{Lv}^{3} \cdot$ Guangxuan $\mathrm{Han}^{1,2} \cdot$ Shuyu $\mathrm{Zhu}^{3} \cdot$ Xiaoling Liu $^{1,2} \cdot$ Andong Wang $^{3} \cdot$ Bo Guan $^{1,2}$. \\ Yajie Zhao ${ }^{3}$
}

Received: 19 January 2020 / Accepted: 28 July 2020 / Published online: 4 September 2020

(C) Society of Wetland Scientists 2020

\begin{abstract}
In the past two decades, the supratidal wetland in the Yellow River Delta experienced severe saline-alkalization and vegetation degradation. Restoration with enclosure-freshwater release mode has prevailed since 2002. This method presented some positive effects, but need a massive freshwater supply. Furthermore, the subsequent formed single Phragmites australis vegetation weakened the bird habitation function. In this study, we developed another restoration mode based on microtopography modification. The core idea of the mode is to enhance micro-habitat heterogeneity thus improve the water resource temporal-spatial distribution and shape more niches. An ecological restoration program was designed and implemented since May, 2015. The monitoring data from July, 2015 to December 2017 showed that, with no extra artificially drained freshwater released, the soil salinity decreased by $15.4 \%$ to $30.8 \%$. The area of bare land decreased while that vegetation and water surface increased, resulting in relative even land cover composition, habitat heterogeneity increased and thus the bird biodiversity improved. This mode is more ecological and water cost-effective and is suitable to restore the degraded saline-alkalized supratidal wetlands. However, longterm comprehensive monitoring is essential to evaluate the restoration effect. Many detailed parameters for topography modification need further optimized.
\end{abstract}

Keywords Supratidal wetland $\cdot$ Ecological restoration $\cdot$ Microtopography modification $\cdot$ Bird diversity $\cdot$ The Yellow River Delta

Electronic supplementary material The online version of this article (https://doi.org/10.1007/s13157-020-01351-z) contains supplementary material, which is available to authorized users.

Guangmei Wang

gmwang@yic.ac.cn

Guangxuan Han

gxhan@yic.ac.cn

1 CAS Key Laboratory of Coastal Environmental Process and Ecological Remediation, Yantai Institute of Coastal Zone Research (YIC), Shandong Key Laboratory of Coastal Environmental Process, YICCAS, Chinese Academy of Sciences (CAS),

Yantai, Shandong 264003, People's Republic of China

2 University of Chinese Academy of Sciences, Beijing 10049, People's Republic of China

3 Administration Bureau of the Yellow River Delta National Nature Reserve, Dongying, Shandong 257091, People's Republic of China

\section{Introduction}

As the most productive ecosystems on earth, coastal wetlands can provide vital ecosystem services such as pollution reduction, storm buffering, fishery production and biodiversity maintenance (Mumby 2006; Costanza et al. 2008; Nagelkerken et al. 2008; Gedan et al. 2011; Ouyang and Guo 2016). However, for located in coastal ecotone and influenced by the sea-land interaction, coastal wetlands are also most sensitive to disturbance and have been suffering from serious degradation due to climate changes and anthropogenic activities, including reclamation, port construction and crude oil and natural gas exploitation, worldwide (Nicholls and Cazenave 2010; Zhang et al. 2010; Barbier 2013). In China, despite the great efforts in coastal wetland conservation and restoration, it is still estimated that about $58 \%$ of the total coastal wetlands area have lost over the past 60 years (Sun et al. 2015). 
Typically, wetland restoration focuses on the three basic elements: water, soil and biota, with the objectives to reestablish the relationship between the biotic and abiotic components and to promote the ecological function and local biodiversity at all levels (Zedler 2000; Gallego Fernández and García Novo 2007). From the methodology point of view, coastal wetland restoration methods can be classified as active restoration, passive restoration and creation (Simenstad et al. 2006; Zhao et al. 2016). These three methods could be used alone or jointly, depending on the type of wetlands and the degradation degree. Furthermore, spatial heterogeneity should be paid great attention, since it may have a significant impact on the efficacy of ecological restoration (Yang et al. 2017; Cui et al. 2018).

The Yellow River Delta wetland is the most complete and extensive early successional wetland ecosystem in China, with significant ecological value and abundant natural resources (Cui et al. 2009; Wang et al. 2012). It is formed by the conjunct affection of unique water flow and sediment of the Yellow River and tidal of Bohai sea (Wang et al. 2011). The specific feature of the wetland is not only its importance in the primary estuary and wetland ecosystem's evolution, but also the important overwintering stopover function for migrating birds (Li et al. 2019).

Located in Shandong Province (Fig. 1), the Yellow River Delta wetland $\left(37^{\circ} 40^{\prime} \mathrm{N}\right.$ to $38^{\circ} 10^{\prime} \mathrm{N}, 118^{\circ} 41^{\prime} \mathrm{E}$ to $\left.119^{\circ} 16^{\prime} \mathrm{E}\right)$ has a warm temperate continental monsoon climate with distinctive seasons and rainy summer. The annual average temperature is $12.1^{\circ} \mathrm{C}$, annual average rainfall is $551.6 \mathrm{~mm}$, evaporation is $1962 \mathrm{~mm}$, and the drought index is up to 3.56 (Cui et al. 2009). However, a significant trend of climate change is observed in this area over the past five decades: the annual precipitation drops by $33.1 \%$ and the average temperature increases by $1.7^{\circ} \mathrm{C}$ compared to 55 years ago (Han et al. 2018). As a result, secondary salinization in this area exacerbated. Furthermore, due to the decreasing flow of the Yellow River, freshwater supply to the wetlands decreased subsequently (Cui et al. 2009). Under the synergism of warming and drying climate and anthropogenic activities, the Yellow River Delta wetland experienced severe degradation in the last two decades (Guan et al. 2013). It was estimated that about $58 \%$ of the supratidal wetland area had become severely saline-alkalized with hardly any vegetation (Cao et al. 2014).

Since 2002, many restoration projects were implemented with enclosure-freshwater release mode. In this restoration method, the vegetation degraded area was enclosed with waterproof, with ring channels supplying water drained from the Yellow River. This method had positive effects on the wetland ecosystem in the initial several years by promoting vegetation restoration and providing suitable habitats for birds (Tang et al. 2006); however, the subsequent excessive propagation of Phragmites australis may harm spatial heterogeneity and diversity (Cui et al. 2009). Furthermore, this restoration method consumes massive freshwater, which is limited by the freshwater shortage in the area. More economic and effective restoration methods thus need to be developed.

For the freshwater shortage is unlikely to be alleviated in a short time (Yang et al. 2017), how to better utilize available water recourse may be more feasible for degraded wetlands restoration. In the area, nearly $70 \%$ of the annual precipitation is concentrated in the period of July to September, and the heavy rainfall events become more frequent in recent years
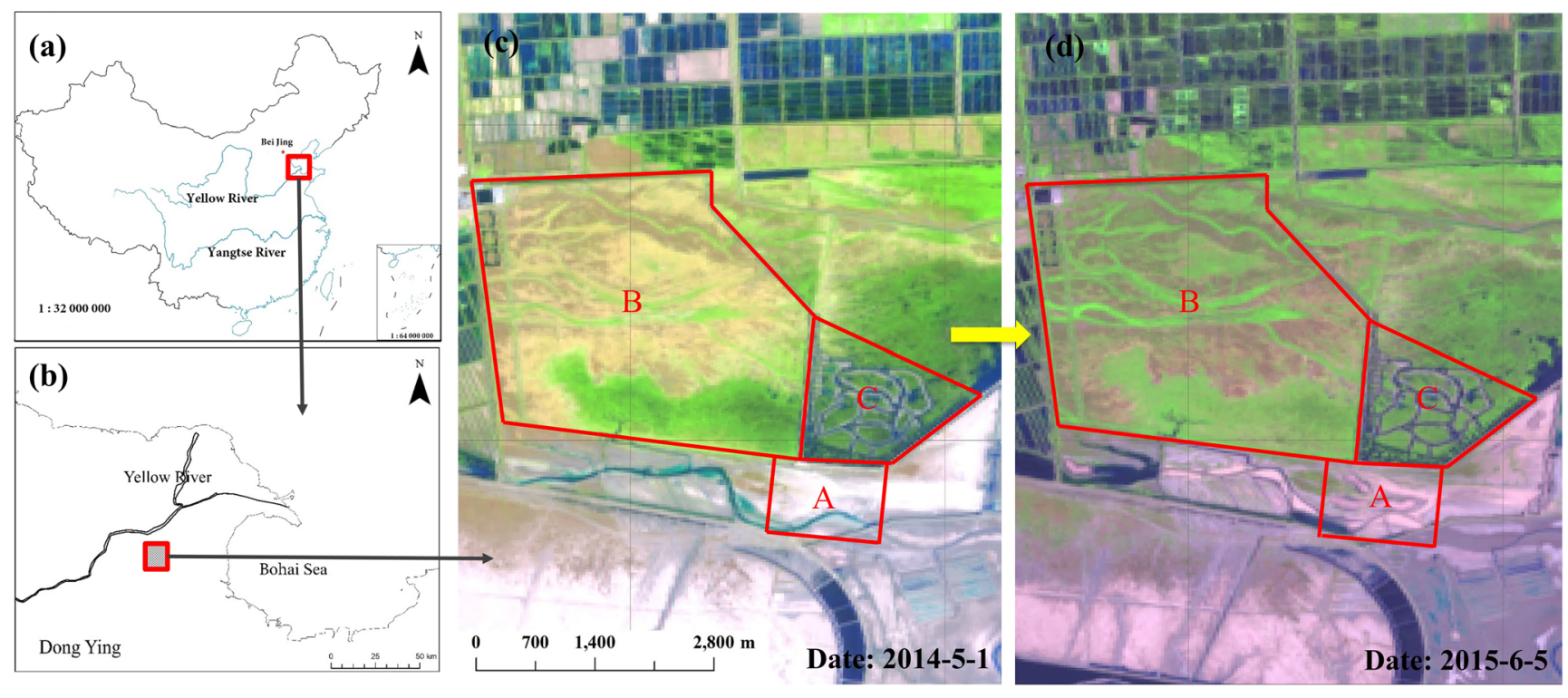

Fig. 1 Study area and the restoration area. a location of the study area in China; b location of the study area in the Yellow River Delta; $\mathbf{c}$ Remote sensing image of the restoration area before the restoration engineering; $\mathbf{d}$ Remote sensing image of the restoration area after the restoration

engineering. The area mark $\mathrm{A}, \mathrm{B}$, and $\mathrm{C}$ are the microtopography modification area, the high vegetation-covered area, and the corridorbuilding area, respectively 
(Han et al. 2018). Due to the flat topography, the area may become whole water surface for the catchment of the runoff in rain season, but could not preserve the water to Winter or Spring for the intense evaporation. Combined with the ecological niche theory, habitat heterogeneity theory, and biodiversity-ecosystem function principle (Lorenzón et al. 2016), we develop a restoration mode based on microtopography modification. The core idea of this mode is to enhance micro-habitat heterogeneity thus improve the water resource temporal-spatial distribution and shape more niches (Fig. 2). Topography modification is performed combined with the state of the area. The soil in the low area was removed to the relatively high area to make habitat islands with gentle slope, while the low area is developed into the catchment zone. In this way, the simple flat topography becomes some undulated and shape heterogeneous habitats accordingly. Gentle slope of the island could enable effective drainage and favoring catchment, and the soil is washed during the drainage-catchment process to relieve salt thus facilitate vegetation restoration. The catchment zone with higher depth could persevere water for longer time and can supply sanctuary for zoobenthos, fishes and birds in dry seasons. The undulating topography and water level gradients also provide various habitats for aquatics, hygrophytes, mesophytes and xerophyte, which therefore enhance the diversity of zoobenthos, fish and birds. In brief, using a simple topography modification method, the precipitation resource may be better utilized and the restoration may be stimulated more economically.

To test the practicability and efficacy of the conceptual restoration mode, we conducted a restoration experiment in a degraded saline-alkalized supratidal wetland from 2015. A restoration engineer according to the restoration mode was completed in May, 2015, and the restoration process thereafter was monitored from July, 2015 to December, 2017. The restoration efficacy was analyzed using the collected data including soil salt content, vegetation, landcover type composition and bird inhabit dynamics. Specifically, the bird inhabit dynamics were compared with the other two neighbor previous restoration zones using other restoration modes. The aim of
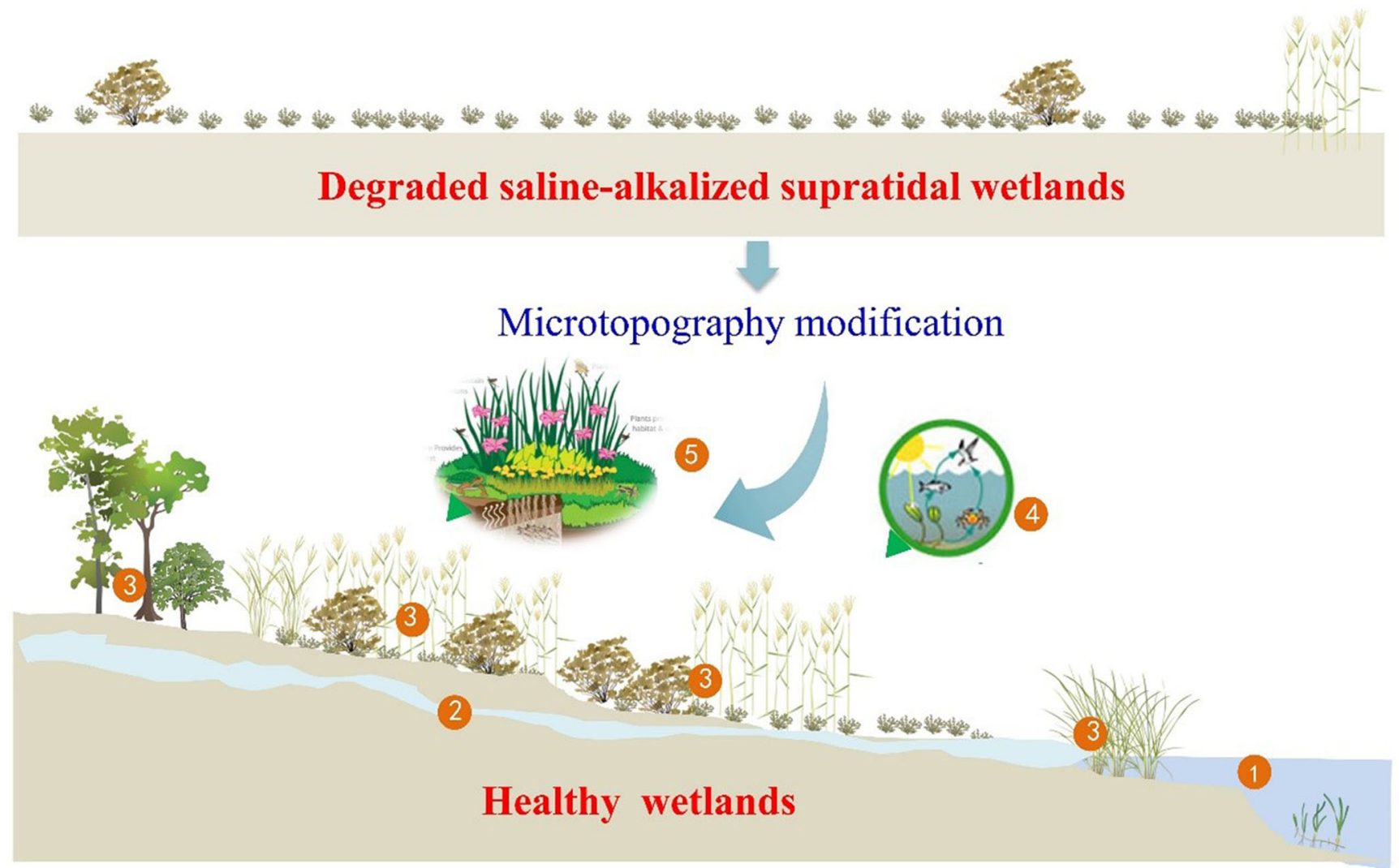

Fig. 2 The conceptual scheme for degraded supratidal saline-alkalized wetland restoration based on microtopography modification. Flat homogeneous supratidal saline-alkalized wetland becomes habitat diversification through topography modification. Ecological restoration thus develops as follow:(1) The low areas are developed into catchment zones which could intercept the surface runoff and the freshwater. Water surfaces can provide habitat for aquatic plants, zoobenthos, fishes and birds. (2) Gentle slope topography of the island could enable effective drainage, thereby promoting the release of soil salt. (3) The undulating topography and water level gradients enhance biodiversity by providing rich habitats for various plants and animals. (4) The improvement of biodiversity and the complexity of food web structure increase the ecosystem stability and further improve the ecosystem service and function. (5) Heterogeneous habitats create a tridimensional structure with diversified landscape and excellent visual effects, thus achieve simultaneous improvement of ecosystem functions and landscape effects 
this research is to develop a more effective and economic method for degraded wetlands restoration in the Yellow River Delta.

\section{Study Site}

\section{The Microhabitats-Modified Area}

The restoration experiment was performed near the Wuwanmu area which was restored with the enclosurefreshwater release mode since 2002 (Hua et al. 2016). The degraded supratidal wetland area is a part of the old channel of the Yellow River with low-flat topography (Fig. 1c). For the terminated freshwater supply and the weakened tidal influences, the supratidal wetland degraded to bare land with severe saline-alkalization. Consequently, the bird habitat function of this area is severely damaged. The topography modification engineer was implemented in May 2015. The total area of the engineering project is about $66.4 \mathrm{hm}^{2}$ (Fig. 1d). Three bird habitat islands were constructed in the areas according to the above-described method. Specifically, the habitat islands had relative altitudes of $2.5-3.0 \mathrm{~m}$ and gentle slopes of $4^{\circ}-6^{\circ}$. For water supply is mainly from the rainy season precipitation and usually shape $1.0-1.5 \mathrm{~m}$ depth water surface, this designed altitude could keep the peak of the habitat islands above the water surface of $1.5-2.0 \mathrm{~m}$. In addition, this altitude and slope need relatively small amount of engineering works while meeting the topography modification need. For instance, if the water reaches the depth to $1.0 \mathrm{~m}$ in rainy season, the gentle slopes of $4^{\circ}-6^{\circ}$ could shape a $10-14 \mathrm{~m}$ width area with gradual water depth from 0 to $1.0 \mathrm{~m}$. Combining with the construction of bird habitat islands, trenches with a depth of $2-2.5 \mathrm{~m}$ and a width of $15-20 \mathrm{~m}$ were constructed in areas 6-10 $\mathrm{m}$ away from the islands. This depth and width could maintain somewhat water preservation capacity with economic engineering amount. The distance 6-10 m away from the islands also reduces the risk of soil slid. The main vegetation in the area were mainly sparsely distributed P. australis and Suaeda salsa. For convenience to descript, the area is called as microhabitats-modified area hereafter.

\section{The Two Previous Restoration Zones}

Located $200 \mathrm{~m}$ away from the microhabitats-modified area, there were two previous restoration zones. One is part of the above-mentioned Wuwanmu restoration area, which was restored with the enclosure-freshwater release mode since 2002 (Hua et al. 2016). This area has a total area of $804.7 \mathrm{hm}^{2}$ surrounded by a deep ring channel with a width of $6 \sim 8 \mathrm{~m}$. As shown in the aerial photo taken in Sep, 2015, over 97.2\% of this area was covered by vegetation (vast majority being P.australis with a little Tamarix chinensis), while only $1.2 \%$ of the area was bare land (Fig. S1). This area is called high vegetation-covered area hereafter. The other restoration area has a total area of $205.4 \mathrm{hm}^{2}$, which was restored with enclosure-freshwater release mode together with the high vegetation- covered area in 2002. In 2013, habitat diversion engineering with corridor-building was conducted. In this study, this area is called corridor-building area. The ratio of the total area of the vegetation was $65.6 \%$, water area $21.0 \%$, and bare land 13.4\% in Sep, 2015 (Fig. S1).

\section{Material and Methods}

\section{Restoration Process Monitoring}

Soil salinity, a major factor affecting vegetation status in the Yellow River Delta, is an important indicator for evaluating restoration efficacy (Tang et al. 2006). In addition, the variation of land cover composition directly affects biodiversity and ecosystem function, thus the varying trend of land cover types is also an important indicator (Yue et al. 2007). Therefore, the variation of soil salinity and land cover composition were monitored in the microhabitats-modified area. The first measure of soil salinity and landcover type composition was conducted on 28 June, 2015, when the topography modification engineer had completed about one month but still before rainy seasons. Since then to December 2017, the measure was performed twice every year. The first time was performed before rainy seasons (late June or early July) and the second time was performed after rainy seasons (early November, in 2015 was performed on September 28).

Furthermore, for the bird habitat function is an important indicator of the wetland wealth status (Zou et al. 2014; Hua et al. 2016), the comparison of bird habitat dynamics, including the species composition, quantity and ecotypes, among the three different restoration areas, can be used to assess the efficacy of different restoration mode. The detailed monitoring of soil salinity, landcover type composition and bird habitat dynamic as follows:

\section{Soil Salinity}

Two fixed transects along the altitude gradient were set on each habitat island (three islands thus six in total). On each transect, three $1 \times 1 \mathrm{~m}^{2}$ fixed quadrats were set at sites with a relative altitude of $0 \mathrm{~m}$ (the lowest site of the island), $0.6 \mathrm{~m}$ and $1.2 \mathrm{~m}$, respectively. Three soil cores with a diameter of $3.8 \mathrm{~cm}$ and a depth from 0 to $20 \mathrm{~cm}$ were randomly collected from each fixed quadrat and thoroughly mixed into one composite sample. As above-mentioned, the soil collection was conducted 6 times in total from June, 2015 to December, 2017. The samples were air-dried and then sieved through a $0.15-\mathrm{mm}$ mesh to measure soil salt contents using the weighing method. 


\section{Landcover Type Composition}

Unmanned Aerial Vehicle (UAV) aerial photo was used to monitor the dynamics of land cover composition and vegetation recovery. On the same day that soil was sampled (six times in total all the same), ortho aerial photo in 1:500 scale of the restoration area was taken by a Sony RX1 full picture camera (24.3 million pixels), which was installed at a fixedwing UAV (XY1800). The flight speed and height of the UAV were set in $25 \mathrm{~m} / \mathrm{s}$ and $900-1000 \mathrm{~m}$, respectively. The interpretation of the aerial photos was executed as follows: 10 control points were established in the restoration area using GPS. The aerial photos were registered according to the control points using UTM_WGS84 50N coordinate system in eCognition Developer 9.0. A mask was developed and the target area was extracted according to the mask. According to the field investigation and the segmentation of the aerial photos, classified area for training was established. The aerial photos were supervised classified using the object-oriented nearest classification method, then the classification results were processed based on records of field investigations to guarantee the accuracy of classification results over $80 \%$. The land cover types were classified into vegetation ( $P$. australis and $S$. salsa), water surface and bare land. Finally, the aerial photos were interpreted using ArcGIS 10.2.

\section{Bird Habitat Dynamic}

Bird surveys were conducted monthly on each of the three study sites from July 2015 to December 2017, covering the two peak migration periods (Spring and Autumn) three times. Bird surveys of the three study sites were carried out on the same day, started $1 \mathrm{~h}$ after sunrise and lasted $4-5 \mathrm{~h}$. Two or three investigators counted birds using $20 \times 60$ telescope and $80 \times$ binoculars from walking at a speed of $1-2 \mathrm{~km}$ per hour. The number of bird species and their population sizes in the three study sites from July 2015 to December 2017 were calculated and analyzed. The species identity and protection class were identified according to Birds of the Yellow River Delta (Liu 2013).

\section{Data Analysis}

The analysis of soil salinity across time was performed by repeated measures ANOVA using time, altitude and their interactions as fixed-effects. One-way ANOVA was used to compare the soil salinity among three altitudes. S-N-K posthoc tests were used to determine the difference level.

The bird species number $(S)$ was recorded as the number of species in each restoration area. Species abundance $(D)$, Shannon index $(H)$ and Pielou index $(J)$ were calculated as:

$$
\begin{gathered}
D=\frac{S}{\ln A} \\
H=-\sum \frac{n_{i}}{N} \ln \frac{n_{i}}{N} \\
J=\frac{H}{\ln S}
\end{gathered}
$$

where $n_{i}$ and $N$ are the individual numbers of species $i$ and all species observed in the restoration areas, respectively, and $A$ is the area of the corresponding observation area. All statistical analyses were performed using SPSS 20.0 for Windows (SPSS Inc., Chicago, IL, USA), and statistical significance was set at $\alpha=0.05$.

\section{Results}

\section{Dynamic Variation of Soil Salinity}

In June 2015 when the topography modification engineer just completed about one month, soil salinity decreased significantly with the increase of soil altitude $(F=14.27$, $P<0.001)$. Repeated measures ANOVA showed that soil salinity at all three altitudes varied drastically over time $(F=$ 42.53, $P<0.001)$, and all of them showed a decreasing trend (Fig. 3). During the restoration processes, soil salinity at the altitude of $0 \mathrm{~m}$ and $0.6 \mathrm{~m}$ were significantly higher than that at the altitude of $1.2 \mathrm{~m}$. Since July 2017, there was no significant difference in soil salinity between the altitudes of $0 \mathrm{~m}$ and $0.6 \mathrm{~m}$. By November 2017, the decreased extent of soil salinity in different altitudes follow the sequence of $0 \mathrm{~m}(30.8 \%)>$ $1.2 \mathrm{~m}(20.0 \%)>0.6 \mathrm{~m}(15.4 \%)$.

\section{Dynamic Variation of Vegetation Area}

After two and a half year's restoration, the total area of vegetation on the three habitat islands increased significantly (Figs. 4 and 5). The area of $P$. australis population increased from $0.14 \mathrm{hm}^{2}$ to $1.67 \mathrm{hm}^{2}$, with the ratio to the overall area of 3 habitat islands increased from $1.1 \%$ to $14.2 \%$. Meanwhile, the area of $S$. salsa population increased by $2.05 \mathrm{hm}^{2}$, with the ratio increased from $0.6 \%$ to $20.7 \%$. In areas outside the habitat island, the areas of S.salsa and P. australis populations increased by $2.1 \mathrm{hm}^{2}(35.2 \%)$ and $6.3 \mathrm{hm}^{2}(52.6 \%)$, respectively (Fig. 5).

\section{Dynamic Changes in the Land Cover Composition}

In 2015-2017, the ratios of both vegetation and water surface before the rainy season increased year by year (Figs. 4 and 6). Specifically, the increase of the ratio of vegetation was from $27.4 \%$ to $44.5 \%$, and water surface from $2.1 \%$ to $14.0 \%$ Meanwhile, the ratio of bare land decreased from $70.6 \%$ to 
Fig. 3 Variation of soil salinity at different altitudes during the restoration process. Data are means $\pm \mathrm{SD}(n=6)$. Different letters from in the same column indicate the significant difference at the $\alpha=0.05$ level

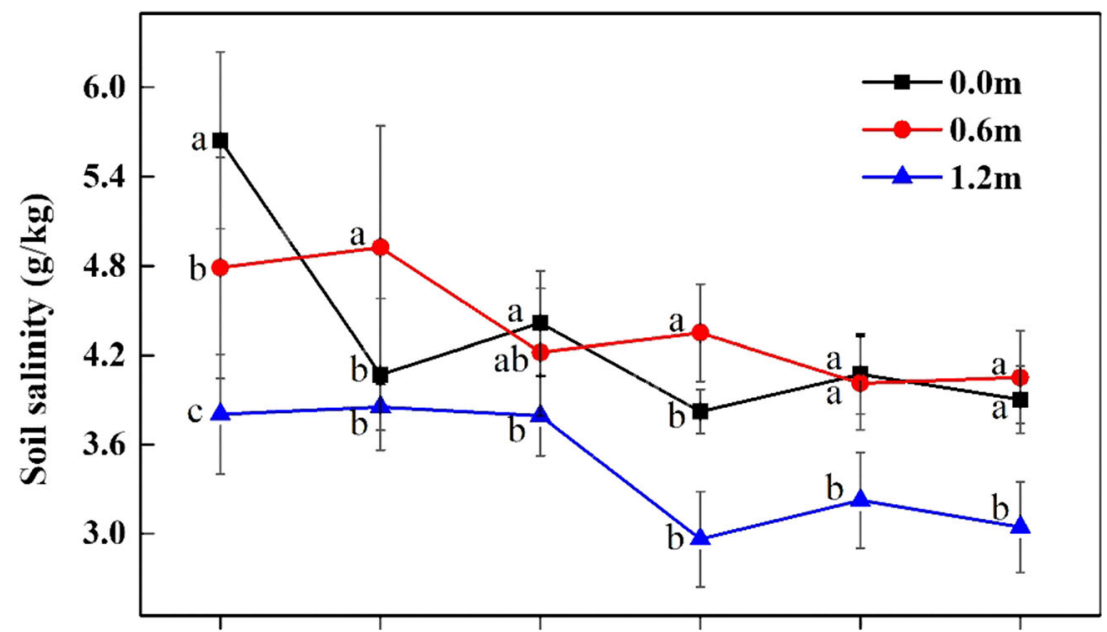

$\begin{array}{lllllll}\text { Jun } 2015 & \text { Sep } 2015 & \text { Jul } 2016 & \text { Nov } 2016 & \text { Jul } 2017 & \text { Nov } 2017\end{array}$
$41.5 \%$. Similarly, the ratio of vegetation after the rain season increased in 2015-2017; the ratio of water surface reached a stable point (ca.16\%) while the ratio of bare land decreased gradually since October, 2016. The low ratio of bare land in 2015 was attributed to the large annual precipitation in that year, while the reduction of the ratio of bare land after 2016 was mainly due to vegetation recovery on bare land.

\section{Bird Habitation Dynamics}

\section{Total Bird Habitation in Three Restoration Areas}

The microtopography-modification area had the highest species number, species abundance, total individual count, and species number of priority protection among the three areas (Table 1). A total of 73 bird species belonging to 21 families were observed in the microtopographymodification area, which accounted for $19.9 \%$ of the total 367 bird species in the Yellow River Delta (Liu 2013). In the corridor-building area, whose area is 3.1 times the microtopography-modification area, the bird species number was $78.1 \%$, species abundance $61.5 \%$ and the total individual $86.4 \%$ of those in microtopographymodification area. In the high vegetation-covered area, though its area is 3.9 times of the corridor-building area and 12.1 times of the microtopography-modification area, respectively, the bird species number and quantity were both significantly lower than those in these two restoration areas. Specifically, the quantity of birds in the area was only equivalent to $0.3 \%$ of those in microtopographymodification area and $0.5 \%$ in corridor-building area, respectively.
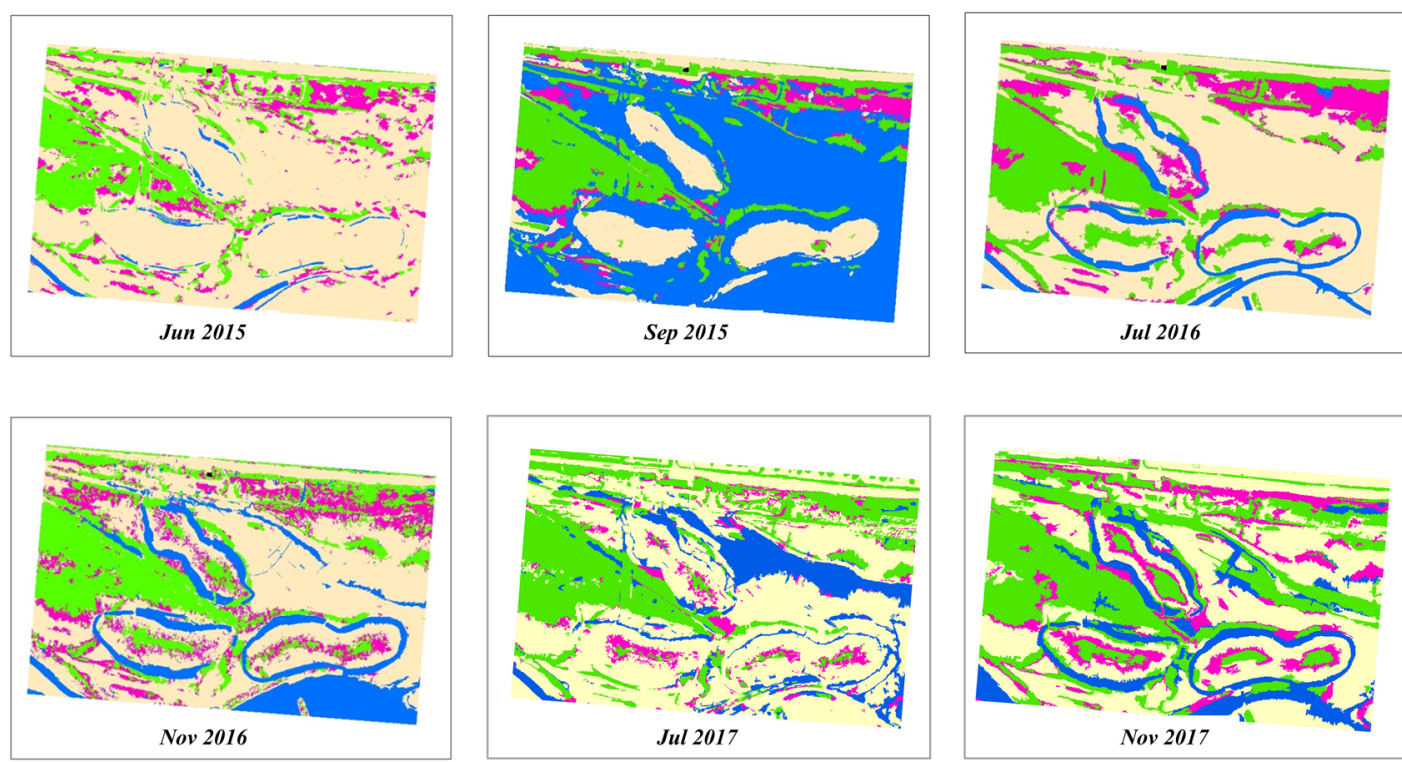

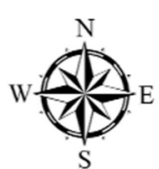

Bare land

Water surface

S. salsa

P. australis

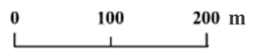

Fig. 4 Dynamic changes of different land cover types in microtopography-modification area during the restoration process 

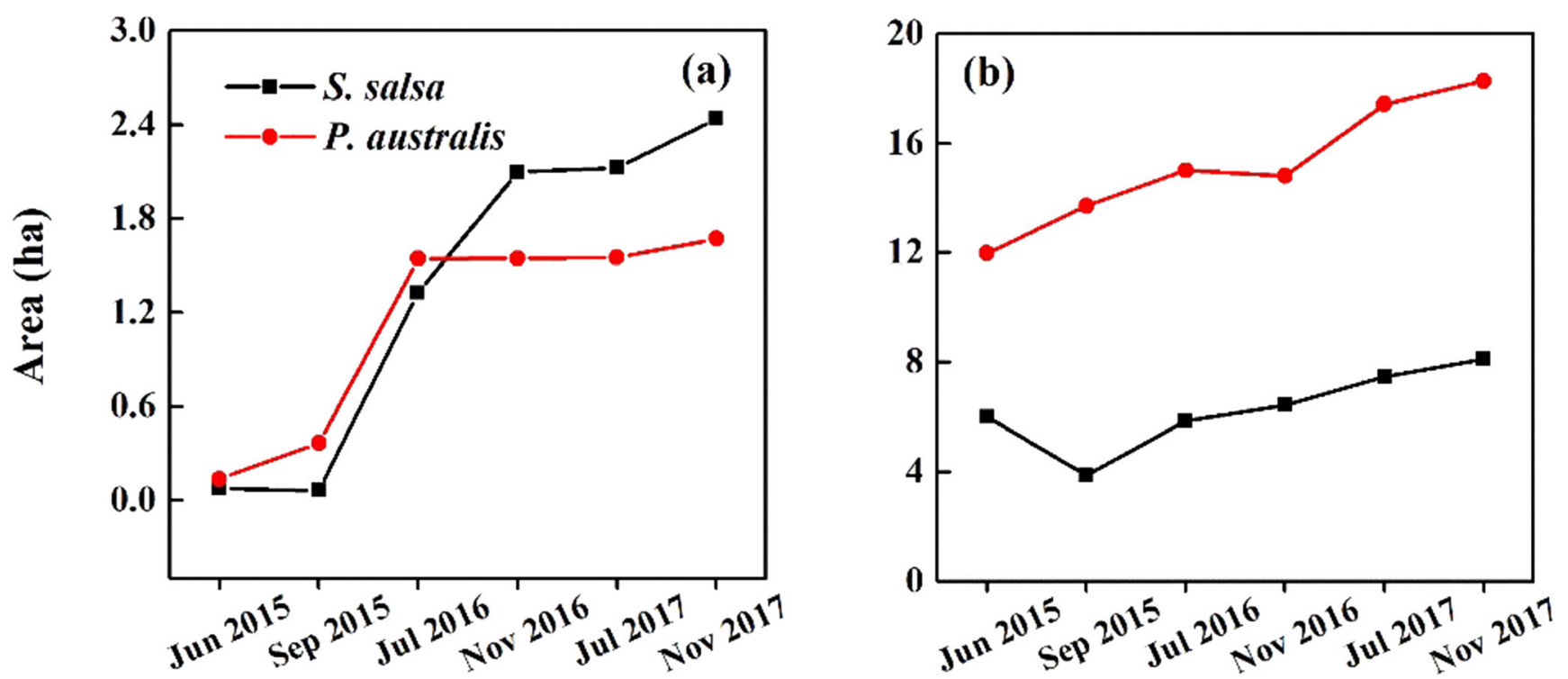

Fig. 5 Area of $S$. salsa and P. australis within (a) and outside (b) the bird habitat islands during the restoration process

As for the birds with priority protection, the 73 birds in the microtopography-modification area (Table S1) included 3 first-class national protection birds (Grus leucogeranus, Grus japonensis and Ciconia boyciana), 11 s-class national protection birds (e.g., Grus grus, Buteo buteo and Platalea leucorodia) and 8 Shandong provincial protection birds (e.g. Ardea purpurea, Ardea cinere and Butorides striatus). Especially, Grus leucogeranus was observed in this area for the first time. In the corridor-building area, $34.5 \%$ of all bird species were priority protected birds, including 3 above mentioned first-class national protection birds, 9-s-class national protection birds and 7 Shandong provincial protection birds (Table S2). In high vegetation-covered area, only 5 Shandong provincial protection birds but no national protection birds were observed (Table S3). In corridor-building area and microtopography-modification area, the species number of priority protection birds had no obvious gap.

\section{Composition of Bird Ecotypes in Three Restoration Areas}

Waterfowl dominated in the microtopography-modification area, followed by wader, with other ecotypes such as raptor, land bird, songbird and climber all present. In corridorbuilding area, waterfowl still dominated with other 4 ecotypes present, while songbird was absent. In high vegetationcovered area, waders dominated, followed by waterfowl, with only one walker and one climber present (Fig. 7).
Fig. 6 Ratio of different land cover types varied during the restoration process

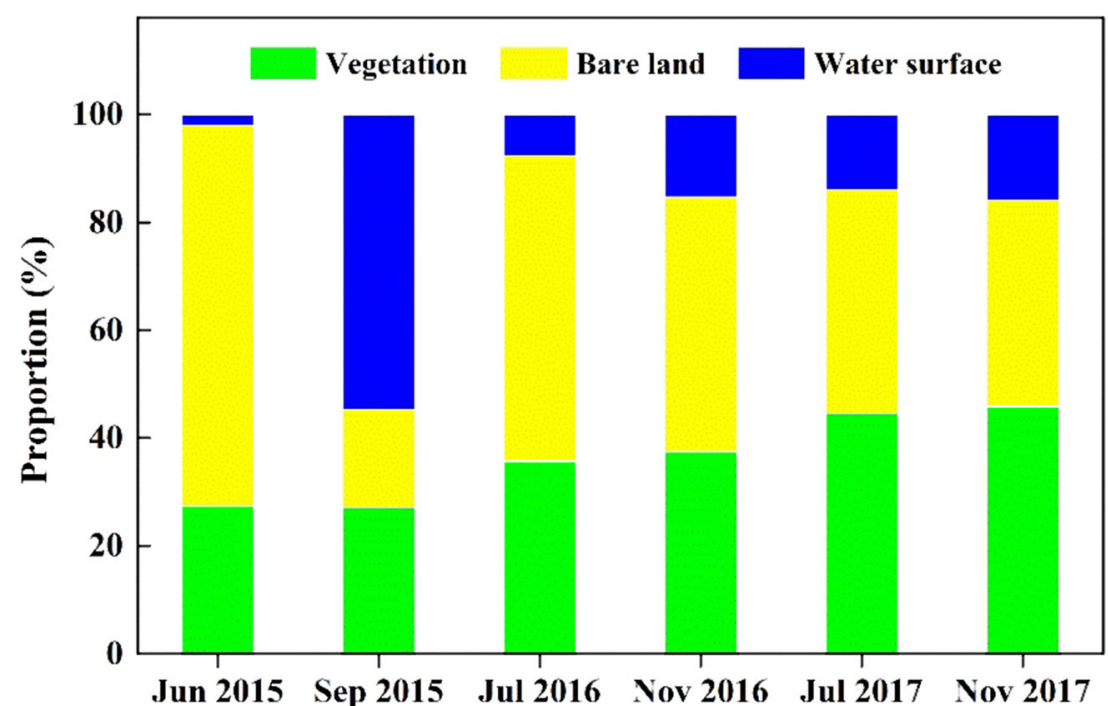


Table 1 The total population characteristics of bird in different restoration areas from July, 2015 to December, 2017

\begin{tabular}{llll}
\hline & Microtopography-modification area & Corridor-building area & High vegetation-covered area \\
\hline Area (ha) & 66.5 & 205.4 & 804.7 \\
Species number & 73 & 57 & 24 \\
Species abundance & 17.39 & 10.70 & 3.59 \\
Total individual count & 180,876 & 156,333 & 578 \\
Number of priority protection species & 22 & 19 & 5 \\
\hline
\end{tabular}

\section{Bird Diversity of Three Restoration Areas during the Migration Period}

The bird diversity during the Spring peak migration period (April) and the Autumn peak migration period (November) in the three restoration areas were shown in Fig. 8. The results demonstrated that, compared with the corridor-building area, the species number and species richness in the microtopography-modification area were significantly higher during the Autumn peak migration period but lower during the Spring peak migration period. However, the species number and species richness of both areas were significantly higher than the high vegetation-covered area (Fig. 8). The Shannon index and Pielou index showed no obvious variation trend, no matter in the comparison among three sites or each particular site along with the restoration process. However, Shannon's index of the microtopography-modification area was almost higher than the other two areas in any specific migration period (except for April, 2017).

\section{Discussion}

\section{Variation of Soil Salinity}

In the supratidal wetland restoration areas, soil salinization frequently decreased thus stimulate vegetation recovery gradually (Cui et al. 2009). In this study, the soil salinity at all three altitudes of the microtopographymodification area decreased, but the decreasing extent was some different. At the $1.2 \mathrm{~m}$ altitude site, the soil was more washed by precipitation and could release more salt, and the relatively high altitude also prevent the soil surface salt accumulation. At the $0 \mathrm{~m}$ altitude area, it was frequently flushed by water in the trench catchment zone. As for the $0.6 \mathrm{~m}$ altitude area, it was influenced by the dual influence of less wash and more accumulation of salt than $1.2 \mathrm{~m}$ altitude site. Therefore, the salt content at $0.6 \mathrm{~m}$ altitude was higher than the other two sites. However, the relatively high soil salt content in this area may beneficial to maintain certain bare land in the habitat island to keep a mosaic habitat.

\section{Vegetation Recovery and Variation of Land Cover Type Composition}

After micro-topography modification, the total area of vegetation increased significantly, no matter in or outside the habitat islands. However, the increase in the area of $S$. salsa was higher than that of $P$. australis in the habitat islands but lower outside the habitat islands (Fig. 5). This variation trend can be attributed to their different ecological adaptability. P. australis is resistant to waterlogging and the rich water supply in the rainy season favors its
Fig. 7 The ecotype composition of birds in different restoration areas

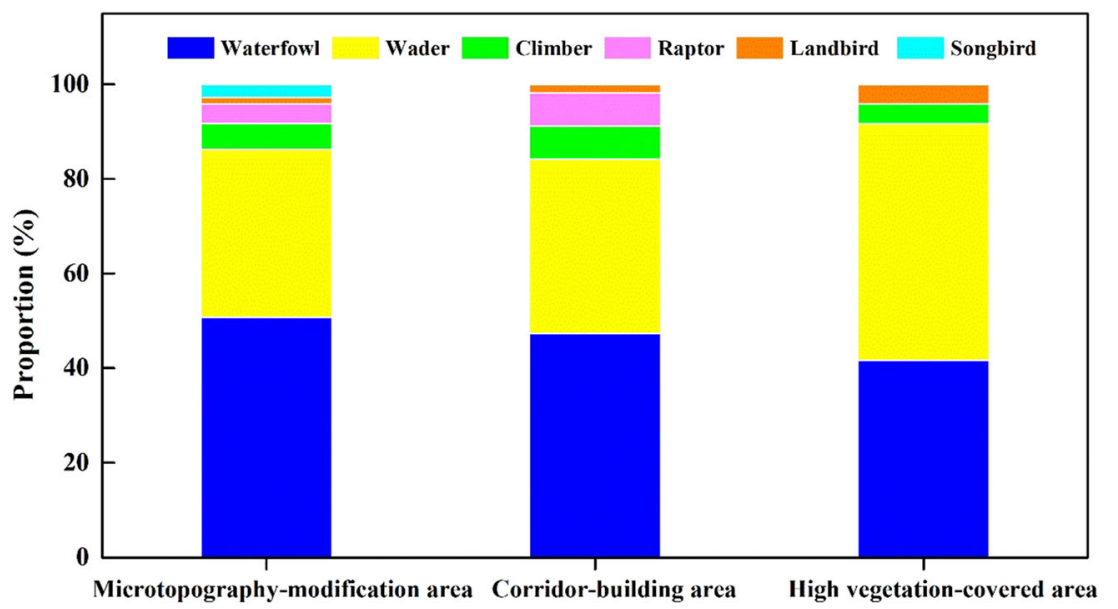




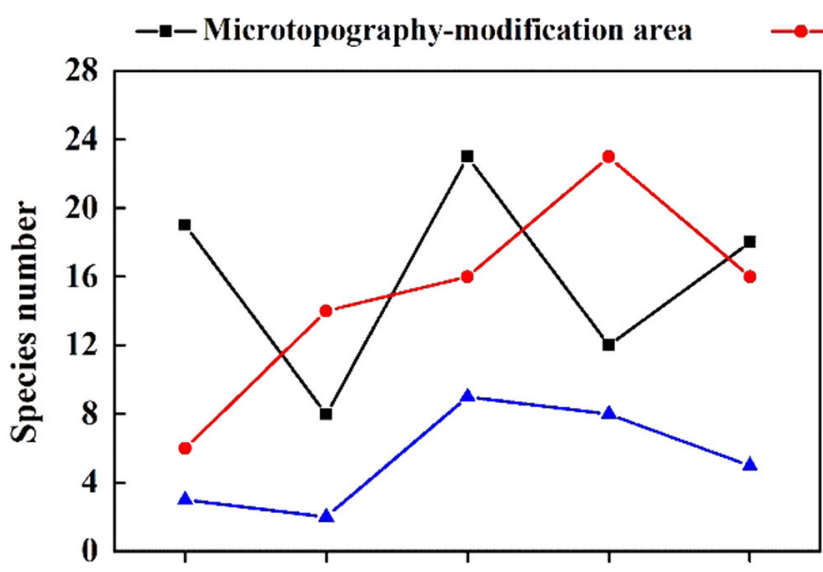

Nov 2015 Apr 2016 Nov 2016 Apr 2017 Nov 2017

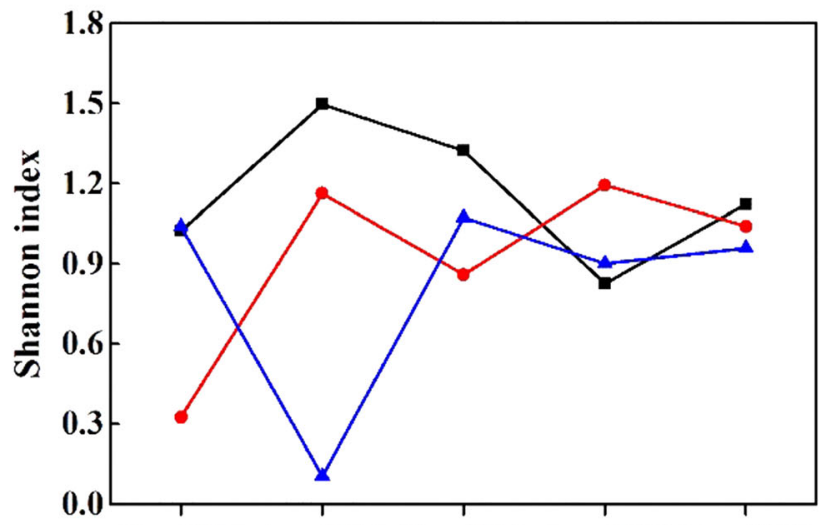

Nov 2015 Apr 2016 Nov 2016 Apr 2017 Nov 2017
- - Corridor-building area

$-\wedge-$ High vegetation-covered area

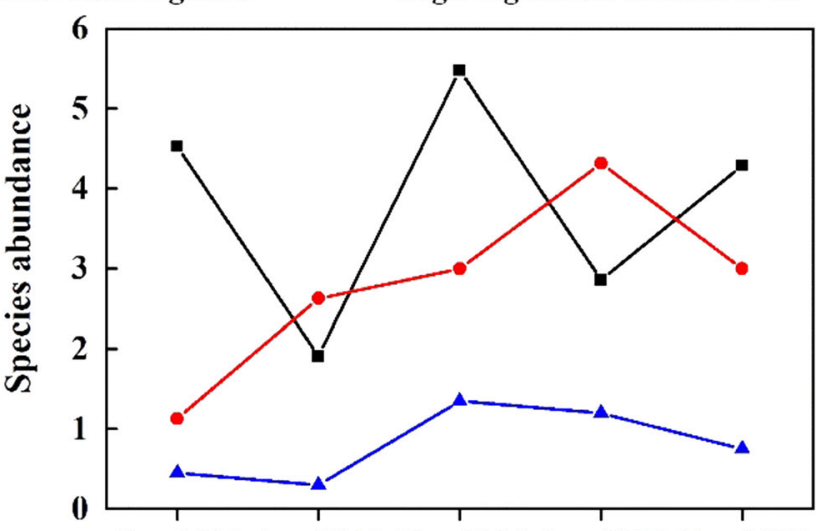

Nov 2015 Apr 2016 Nov 2016 Apr 2017 Nov 2017

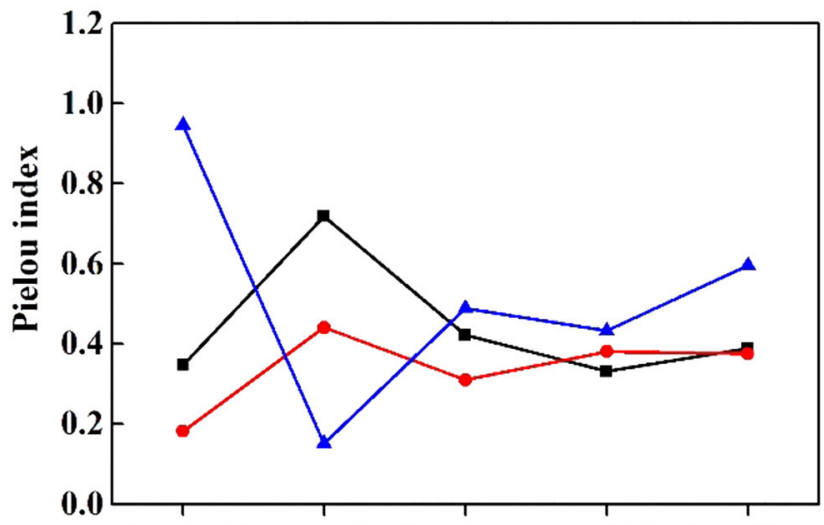

Nov 2015 Apr 2016 Nov 2016 Apr 2017 Nov 2017

Fig. 8 Species number, species abundance, Shannon index and Pielou index of bird community in different restoration areas during peak migration periods

survival and reproduction (Yang et al. 2017). S. salsa is more adaptable to dry environments but would gradually die once being waterlogged (Hua et al. 2016). Hence, $S$. salsa can only be maintained in areas above the water level and will not be expanded to waterlogged areas in rainy seasons. In addition, though the vegetation cover was mainly observed for the two dominant species from aerial photos, other plant species may present gradually for the improved environmental condition and increasing propagation opportunities of propagules (Tang et al. 2006).

After micro-habitation modification, vegetation area expanded significantly, resulting in a gradual decrease in the ratio of bare land. On the other hand, due to the construction of the trench catchment zone, the water resource preservation ability improves, which benefit to keep certain water surface before and after the rainy season. Therefore, the microtopography modification leads to more even composition of different land cover types, thus facilitate the biodiversity improvement in this area. Such pattern was also observed in the restoration trial of bird habitat on the intertidal flats in the Yangtze Estuary (Gao and $\mathrm{Lu}$ 2008; Zou et al. 2014)

\section{Bird Habitation Function of Different Restoration Modes}

The results demonstrated the advantage of the microtopography-modification area over the other two areas in bird habitation function. The populations, compositions and distributions of birds are closely related to their habitats (Lorenzón et al. 2016; Luo et al. 2019). Water area, bare land and vegetation are the three key components affecting bird habitation (Farrell et al. 2010). The water depth is directly related to the habitats of different bird ecotypes. For instance, shorebirds prefer shoal habitat, while waterfowl such as Anas poecilorhyncha prefer open water habitat (Mammides et al. 2015). The ratio of shallow water area and bare land is also a key factor affecting the distribution of shorebirds. Vegetation in wetlands provides shelters, nesting sites and food for birds. A suitable ratio of vegetation could supply favorable resting and foraging habitats, however, both over-high and over-low vegetation coverage can negatively affect bird's foraging efficiency (Stirnemann et al. 2015). In this study, the microtopography modified area could shape appropriate water depth gradients and vegetation coverage to enhance habitat diversity. The trench catchment zone maintains a certain area 
of water surface thus provide sanctuary for fish and foraging places for waterfowl in the dry season, while the habitat islands can supply bare land to satisfy rest need for other birds. Compared with the other two restoration modes, the ratio of vegetation, bare land and water area in the micro-topography modification area can be maintained at a relative appropriate level. Therefore, the species number, total individual count and ecotypes in this area were higher than the other two areas. In summary, the ecological restoration mode based on microtopography modification is more suitable for this kind of degraded saline-alkalized supratidal wetland to improve the bird habitation function.

This result also testified that the bird habitat function suffers from simplified habitat (Stirnemann et al. 2015), especially in the $P$. australis single-dominated circumstance. This problem could be partly alleviated by habitat diversion engineering such as corridor-building. Though this mode did not build water depth gradients, the corridor-building area had a bird diversity nearly equivalent to the microtopographymodification area especially in terms of the rare and endangered birds, which is significantly higher than the high vegetation-covered area. More comprehensive habitat diversion schemes, including more consideration on water depth gradient and bare land construction, need to be developed in the future management on high vegetation- covered area.

However, the Shannon index and Pielou index showed no obvious difference in variation trends among the three restoration areas during the migration period. This may be attributed to the bird transfer station function of the Yellow River Delta wetland. The migration time of many bird species may coincide, resulting in some species arriving with large and clustered populations but some species with a small population. As a result, Shannon index and Pielou index could be quite different.

\section{Implications for Management}

Wetland restorations should consider the entire ecosystem to promote local biodiversity at all levels, but not just some components or certain species group (Gallego Fernández and García Novo 2007). Furthermore, it should account for resource availability and the cost-efficiency. In the Yellow River Delta, for insufficient water resource, the freshwater release is regulated based on supply-side management (i.e. availability) rather than on the water requirement (Yang et al. 2017). In this study, the microtopography-modification mode we developed can effectively store summer precipitation, regulate the land cover composition proportion to a suitable level, increase habitat heterogeneity and improve the bird biodiversity. Actually, from July 2015 to December 2017, the microtopography modified area received no extra artificially drained freshwater. All the water surface was formulated through precipitation and the interception of surface runoff. Compared with the enclosurefreshwater release mode, this mode is more ecological and water cost-efficient. In 2016, another three new bird habitat islands using this mode were constructed, resulting in the great promotion of reproduction of certain target birds (e.g., Larus saundersi) while accelerated vegetation restoration.

Though the microtopography-modification mode presents certain positive effects in the first 2.5 years, there are still many issues need further study. For instance, how macrobenthos and fish respond during the restoration process? How to optimize the slope and altitude of the habitat islands? What is the optimal ratio of vegetation, water surface and bare land to further improve the bird habitation function? Studies involved such questions and the detailed comparison of the cost-efficiency of different restoration modes would benefit much to future wetland management and restoration.

\section{Conclusion}

Previous enclosure-freshwater release method for degraded supratidal wetland restoration in the Yellow River Delta has some positive effects, but was limited by the water resource shortage in the area. The subsequent excessive propagation of $P$. australis also weakens the bird habitation function. With a core idea to improve water resource temporal-spatial distribution and shape more niches, a restoration mode based on microtopography modification to enhance micro-habitat heterogeneity was developed. In 2.5 years from 2015 to 2017, this restoration method stimulated vegetation recovery, regulated the land cover composition, increased habitat heterogeneity and then improved the bird biodiversity of the degraded supratidal wetland. This method is more ecological and water cost-efficient and could have important implications for the degraded saline-alkalized supratidal wetlands restoration. However, long-term monitoring is essential to evaluate the effect comprehensively, and many detailed parameters for topography modification need further optimized.

Acknowledgments This work was funded by the National Key Research \& Development Program of China (2019YFD1002702), the Key Research Program of the Chinese Academy of Sciences(KFZD-SW113), the Strategic Priority Research Program of the Chinese Academy of Sciences (XDA23050202) and the Habitat and Bird Dynamics Monitoring Project of the Yellow River Delta National Reserve (Y991021021). We would like to thank Yunzhao Li, Xiaojie Wang and Dongxue $\mathrm{Yu}$ for their help in aerial photo interpretation, and thank Wei Ren, Yuenan Ran, Dehua Qi for field work.

\section{References}

Barbier EB (2013) Valuing ecosystem Services for Coastal Wetland Protection and Restoration: Progress and challenges. Resources 2: 213-230. https://doi.org/10.3390/resources2030213

Cao JR, Xu XG, Yu HJ, Liu YJ (2014) Analysis for driving forces and ecological risk assessment of soil salinization in the Yellow River 
Delta. Advances in Marine Science 32(4):508-516. https://doi.org/ 10.3969/j.issn.1671-6647.2014.04.008

Costanza R, Pérez-Maqueo O, Martinez ML, Sutton P, Anderson SJ, Mulder K (2008) The value of coastal wetlands for hurricane protection. Ambio: A Journal of the Human Environment 37(4):241248. https://doi.org/10.1579/0044-7447(2008)37[241:tvocwf]2.0. $\mathrm{co} ; 2$

Cui BS, Yang QC, Yang ZF, Zhang KJ (2009) Evaluating the ecological performance of wetland restoration in the Yellow River Delta, China. Ecological Engineering 35(7):1090-1103. https://doi.org/ 10.1016/j.ecoleng.2009.03.022

Cui LL, Li GS, Ouyang NL, Mu FY, Yan F, Zhang YT, Huang XY (2018) Analyzing coastal wetland degradation and its key restoration Technologies in the Coastal Area of Jiangsu, China. Wetlands 38(3):525-537. https://doi.org/10.1007/s13157-018-0997-6

Farrell JM, Murry BA, Leopold DJ, Halpern A, Rippke MB, Godwin KS, Hafner SD (2010) Water-level regulation and coastal wetland vegetation in the upper St. Lawrence River: inferences from historical aerial imagery, seed banks, and Typha dynamics. Hydrobiologia 647(1):127-144. https://doi.org/10.1007/s10750-009-0035-z

Gallego Fernández JB, García Novo F (2007) High-intensity versus lowintensity restoration alternatives of a tidal marsh in Guadalquivir estuary, SW Spain. Ecological Engineering 30(2):112-121. https:// doi.org/10.1016/j.ecoleng.2006.11.005

Gao W, Lu JJ (2008) A restoration trial of bird habitat on the intertidal flats in the Yangtze estuary and its short-term effects. Acta Ecologica Sinica 28(5):2080-2089

Gedan KB, Kirwan ML, Wolanski E, Barbier EB, Silliman BR (2011) The present and future role of coastal wetland vegetation in protecting shorelines: answering recent challenges to the paradigm. Climatic Change 106(1):7-29. https://doi.org/10.1007/s10584-0100003-7

Guan B, Yu JB, Cao D, Li YZ, Han GX, Mao PL (2013) The ecological restoration of heavily degraded saline wetland in the Yellow River Delta. Clean: Soil, Air, Water 41(7):690-696. https://doi.org/10. 1002/clen.201200569

Han GX, Sun BY, Chu XJ, Xing QH, Song WM, Xia JY (2018) Precipitation events reduce soil respiration in a coastal wetland based on four-year continuous field measurements. Agricultural and Forest Meteorology 256-257:292-303. https://doi.org/10. 1016/j.agrformet.2018.03.018

Hua YY, Cui BS, He WJ, Cai YZ (2016) Identifying potential restoration areas of freshwater wetlands in a river delta. Ecological Indicators 71:438-448. https://doi.org/10.1016/j.ecolind.2016.07.036

Li XW, Hou XY, Song Y, Shan K, Zhu SY, Yu XB, Mo XQ (2019) Assessing changes of habitat quality for shorebirds in stopover sites: a case study in Yellow River Delta, China. Wetlands 39(1):67-77. https://doi.org/10.1007/s13157-018-1075-9

Liu YL (2013) Birds of the Yellow River Delta. China Forestry Publishing House, Beijing

Lorenzón RE, Beltzer AH, Olguin PF, Ronchi-Virgolini AL (2016) Habitat heterogeneity drives bird species richness, nestedness and habitat selection by individual species in fluvial wetlands of the Paraná River, Argentina. Austral Ecology 41(7):829-841. https:// doi.org/10.1111/aec.12375

Luo K, Wu ZL, Bai HT, Wang Z (2019) Bird diversity and waterbird habitat preferences in relation to wetland restoration at Dianchi Lake, south-west China. Avian Research 10(1):1-12. https://doi. org/10.1186/s40657-019-0162-9

Mammides C, Kadis C, Coulson T (2015) The effects of road networks and habitat heterogeneity on the species richness of birds in Natura 2000 sites in Cyprus. Landscape Ecology 30(1):67-75. https://doi. org/10.1007/s10980-014-0100-5

Mumby PJ (2006) Connectivity of reef fish between mangroves and coral reefs: algorithms for the design of marine reserves at seascape scales.
Biological Conservation 128(2):215-222. https://doi.org/10.1016/j. biocon.2005.09.042

Nagelkerken I, Blaber SJM, Bouillon S, Green P, Haywood M, Kirton LG, Meynecke JO, Pawlik J, Penrose HM, Sasekumar A, Somerfield PJ (2008) The habitat function of mangroves for terrestrial and marine fauna: a review. Aquatic Botany 89(2):155-185. https://doi.org/10.1016/j.aquabot.2007.12.007

Nicholls RJ, Cazenave A (2010) Sea-level rise and its impact on coastal zones. Science 328(5985):1517-1520. https://doi.org/10.1126/ science. 1185782

Ouyang XG, Guo F (2016) Paradigms of mangroves in treatment of anthropogenic wastewater pollution. Science of the Total Environment 544:971-979. https://doi.org/10.1016/j.scitotenv. 2015.12.013

Simenstad C, Reed D, Ford M (2006) When is restoration not?: incorporating landscape-scale processes to restore self-sustaining ecosystems in coastal wetland restoration. Ecological Engineering 26(1): 27-39. https://doi.org/10.1016/j.ecoleng.2005.09.007

Stirnemann I, Mortelliti A, Gibbons P, Lindenmayer DB (2015) Finescale habitat heterogeneity influences occupancy in terrestrial mammals in a temperate region of Australia. PLoS One 10(9):1-16. https://doi.org/10.1371/journal.pone.0138681

Sun ZG, Sun WG, Tong C, Zeng CS, Yu X, Mou XJ (2015) China's coastal wetlands: conservation history, implementation efforts, existing issues and strategies for future improvement. Environment International 79:25-41. https://doi.org/10.1016/j.envint.2015.02. 017

Tang N, Cui BS, Zhao XS (2006) The restoration of reed (Phragmites australis) wetland in the Yellow River Delta. Acta Ecologica Sinica 26(8):2616-2624

Wang X, Zhang J, Shamsuddin S et al (2011) Gini coefficient to assess equity in domestic water supply in the Yellow River. Mitigation and Adaptation Strategies for Global Change 17:65-75. https://doi.org/ 10.1007/s11027-011-9309-7

Wang XG, Lian Y, Huang C, Wang XJ, Wang RL, Shan K, Pedroli B, van Eupen M, ElMahdi A, Ali M (2012) Environmental flows and its evaluation of restoration effect based on LEDESS model in Yellow River Delta wetlands. Mitigation and Adaptation Strategies for Global Change 17(4):357-367. https://doi.org/10. 1007/s11027-011-9330-x

Yang W, Li XX, Sun T, Yang ZF, Li M (2017) Habitat heterogeneity affects the efficacy of ecological restoration by freshwater releases in a recovering freshwater coastal wetland in China's Yellow River Delta. Ecological Engineering 104:1-12. https://doi.org/10.1016/j. ecoleng.2017.04.007

Yue TX, Fan ZM, Liu JY (2007) Scenarios of land cover in China. Global and Planetary Change 55(4):317-342. https://doi.org/10.1016/j. gloplacha.2006.10.002

Zedler JB (2000) Progress in wetland restoration ecology. Trends in Ecology \& Evolution 15(10):402-407. https://doi.org/10.1016/ S0169-5347(00)01959-5

Zhang XG, Xu ZZ, Zhang ZH, Gu DQ, Ye SY (2010) Review on degradation of coastal wetlands of northern China Sea. Geological Review 56(4):561-567

Zhao QQ, Bai JH, Huang LB, Gu BH, Lu QQ, Gao ZQ (2016) A review of methodologies and success indicators for coastal wetland restoration. Ecological Indicators 60:442-452. https://doi.org/10.1016/j. ecolind.2015.07.003

Zou Y, Liu J, Yang XT, Zhang M, Tang CD, Wang TH (2014) Impact of coastal wetland restoration strategies in the chongming dongtan wetlands, China: Waterbird community composition as an indicator. Acta Zoologica Academiae Scientiarum Hungaricae 60(2):185-198

Publisher's Note Springer Nature remains neutral with regard to jurisdictional claims in published maps and institutional affiliations. 